\title{
Application Features and Prospect Analysis of Electronic Information Technology
}

\author{
Chunxia Shi ${ }^{1}$, Chunfang $\mathrm{Gao}^{1}$, Linyun Shi ${ }^{1}$ \\ ${ }^{1}$ Baoji Vocational Technology College, Baoji Shaanxi, 721013, China
}

\begin{abstract}
Key words: Electronic information technology, Development status, Application features, High technology, Development prospect.
\end{abstract}

\begin{abstract}
The 21st century is an era of electronic information technology. Therefore, the mastery of application features of electronic information technology and prospect analysis become the hottest research topic of human beings in the new era. This paper briefly discusses the development status of electronic information technology at home and abroad and its application features and focuses on discussing the future trend of various countries in the world in the development of high technology of electronic information.
\end{abstract}

\section{Introduction}

The reason why electronic information technology can replace traditional production technical means in the $21^{\text {st }}$ century is that it follows up fast-paced development demands of the era and provides more data information for human beings and can measure the comprehensive development strength of the state for the convenience of mutual communication and joint progress. Electronic information technology is applied in almost each field of the society. This shows that human beings cannot be separated from its development and application. Therefore, it is necessary to conduct scientific analysis on its application features and prospect and lay a foundation for better future development of human beings.

\section{Connotations and development status of electronic information technology}

\section{Basic connotations of electronic information technology}

The understanding of "information" should centre on the motion state of things and the statement of their subject within the scope of the world, which shows a status manifestation of things in common form. People are generally willing to transfer and handle things and objects with text, data or signal. For example, computer multimedia technology and network technology are electronic technologies that can realize information transmission and processing, also called as electronic information technology. Electronic information technology is all-inclusive. It has fully covered the production and life of human beings currently, such as communication technology, sensor technology, computer technology, signal processing technology, micro electronic technology, audio and video technology, special information technology and software technology etc. Electronic information technology can realize countless functions and objectives. It has even become a part of human life.

\section{Development status of electronic information technology at home and abroad}

Developed countries have started their study on the application of electronic information technology in production and life after the popularization of home computer since 1980s and 1990s.For example, America put forward the ambitious plan of building global information infrastructures at the level of national information economic construction and meanwhile emphasized the comprehensive 
development and upgrade of American military informatization in their star wars program. These measures changed the world pattern of scientific and economic development, allowed many countries to get into the rank of information highway construction very early and laid a foundation for informatization development of human society in the $21^{\text {st }}$ century. In addition, European countries developed industrial structure patter based on the integration of science \& technology, economy and network contact in 1990s so as to achieve joint development of Europe in the field of high and new technology. With the improvement of level of Chinese national economy, electronic information technology has gradually entered the Chinese market and national production and life at the end of 1990s.China has started to introduce various advanced electronic information technologies from foreign countries and gradually penetrated them into all walks of life so as to catch up with era development trend of the world. However, China is relatively backward at the level of joint development of global electronic information technology and still shoulders heavy responsibilities in independent research and development of electronic information technology. According to the development status, China is inclined to effective transformation between machinery and microelectronics and expects to realize intelligentization and automation of equipment operation in some industries and save time and improve efficiency of mass production. This meets development demands of Chinese national conditions ${ }^{[1]}$.

\section{Analysis on application features of electronic information technology}

Electronic information technology has rich types. They have certain similarities in application features. Their technical application features become more and more diversified in the constant invention and study process of human beings, specifically shown as below:

\section{Integration of intelligentization and automation}

Modern electronic information technology presents the development trend of integration of intelligentization and automation, which has strong compatibility, wide scope of application and easier operation procedure and is very suitable for habits and requirements of modern people for the application of electronic information technology. For example, cloud storage technology was born from traditional internet and is located in the rear end of computer network system. From functional perspective, it can provide users with massive data information processing and storage functions and alleviate the pressure of system server. In the current "cloud era", there are wider network user group, increasing user order of magnitude and huge network information throughput. The technology with integration of intelligentization and automation realized by cloud storage in combination with cloud computing technology can make fast reaction to user request. It has linear optimization advantage based on each system function and allows the system to be adapted to various network application environments and guarantee the effectiveness and quickness of data information transmission at any time. More importantly, it has realized the advantage of both intelligent and automatic application and can provide people with automation control digital platform based on remote operation and provide users with intelligent consultation services at any time and in any place. These are functions that cannot be realized by traditional storage architectural system.

\section{Micro integration}

Micro integration mainly aims at the development of traditional semiconductor technology. Among traditional electronic information technologies, semiconductor technology preliminarily presents effective compatibility of micro integrated circuit and integration technology. However, modern electronic information technology has higher technical requirements for relevant contents of semiconductor. First, the circuit of all equipment has basically realized integration under the background of electronic information technology. Sensor is completed based on composite and high polymer material technology. In terms of automatic sensor, it was born for detection. It specially measures information data perceived by the system, conducts data exchange according to the information perceived and collected, finally judges out the specific amount of information contained 
and then conducts relevant work such as later transmission, display, storage and processing. Let' s take temperature sensor for example. It can perceive accurate temperature of the environment rapidly. It has very sensitive measuring elements and does not contact with any object in non-contact measurement process. The main reason is that it has micro integration elements with high sensitivity. This is good for reducing manual measurement error and saving human resources and time.

\section{Network digitalization}

Network digitalization is mainly manifested at computer level. As a main item in electronic information technology, it is coordinated with network technology and lays technical theoretical and practical foundation for electronic information technology. Global coverage of network digitalization has been realized basically so far. Wireless communication technology has made great contributions. It has basically realized full-scope promotion and coverage of data information transmission process and greatly promoted the construction of resource and information sharing mechanism on a global scale. Meanwhile, it has high application safety and reliability. Let' s take digital storage technology for example. It cooperates with current big data and cloud computing technology, provides more convenient digital support space for rapid development of electronic information technology and makes the application of electronic information technology more flexible and varied.

\section{Efficiency and rapidity}

Electronic information technologies stress high efficiency and rapidity which are also realistic demands of human beings for social development in the $21^{\text {st }}$ century. The integration of network technology, sensor technology, wireless communication technology and geographic information positioning technology makes electronic information technology rapider and more efficient and practical. This is leap-type qualitative change for traditional electronic information technology ${ }^{[2]}$.

\section{Analysis on development prospect of electronic information technologies in various countries}

For the development prospect of electronic information technology, various countries in the world have taken corresponding action and put forward development objectives based on their national conditions. The following mainly involves the development prospect of electronic information technology in China and foreign countries.

\section{Analysis on development prospect of electronic information technology overseas}

Since the entry into the $21^{\text {st }}$ century, overseas developed countries have been endeavoring to develop electronic information technology. Korea has gathered all scientific research forces including the government, enterprises and colleges and universities and established national cutting-edge technology development plan (HAN technology) in order to enter the rank of leading developed countries in the world in the $21^{\text {st }}$ century. Technical object directed by this plan includes 11 projects. The top 5 projects are product technical development projects which aim at developing Korean domestic and world industrial market to the greatest extent and improving the economic benefit of their own high-tech products. The later 6 projects are mainly basic technical development projects which mainly occur as core technologies required for improving economic level and living standard of people. Four electronic information technologies are involved, including wireless communication technology, sensor technology, micro electronic technology and optical fiber technology. This indicates that Korea expects to completely enter full-digital information age in the $3^{\text {rd }}$ ten years of the $21^{\text {st }}$ century, complete electronic information technical revolution while in the lead of Asia, create higher social and economic benefits for national development and occupy a more favorable position in the world.

European and American countries are highly developed in industrial development. However, compared to extensive development pattern in the $20^{\text {th }}$ century, they have started to take intensive path and regarded micro electronic technology as priority among priorities of their development in the field of electronic information technology since the $21^{\text {st }}$ century. Let' $\mathrm{s}$ take integrated circuit 
system for example. It has added more micro electronic elements in terms of technological details, such as computer aided design technology (IC-CAD) and exclusive circuit design technology (ASIC).Considering that the development level of electronic integrated circuit technology will restrict the development of national light and heavy industry directly and influence national traffic communication, energy development and military defense modernization level, countries such as America, Britain, Germany and Japan have successively executed the development plan of intelligent integrated circuit technology, put forward electronic information technology development plans such as very high speed integrated circuit, SEMATECH and JESSI and meanwhile updated the study on edge composite information technology. For example, large-scale automation of engineering and remote control technology have basically realized effective integration of engineering project internet information technology. Industrial and agricultural development of America has completely realized automation. Centering on digitalization technology, industry has transformed into modern intermittent process automation from traditional continuous process automation, comprehensive control development from traditional single-machine control, and mini system expansion gradually from large scale system. Therefore, current industrial and agricultural development of America mainly takes the path of intelligent intensive automation system operation. Their small-scale system mainly involves distributed control DCS system. Its industrial production efficiency under technological background has increased greatly.

To cater for global green and environmental development strategies, USA has first put forward a new electronic material with high additional value which provides brand new possibility for effective development of electronic information technology. This is also the new development strategy of America in the $21^{\text {st }}$ century. America has also put forward a ten billion US dollar budget plan for studying and developing new material process, which mainly involves electronic material and metal material. Its research emphasis is to produce new electronic packaging material with wider application through the integration of new material and electronic computer components and parts and meanwhile save resource costs and win larger space for rapid development of electronic information technology.

\section{Analysis on domestic electronic information technology development prospect}

Currently, electronic information technology has a bright development prospect in China. Since the entry of China into WTO, its domestic electronic information market has been geared to international standards and made great breakthroughs in the field of technical research and development. It is expected to seek for technological innovation in the following three fields:

First, computer multi-core technology. It is the key of advanced electronic information technology Computer multi-core development plays a great role in the improvement of computer volume and computational efficiency. Specifically, it is a critical update of computer processor which expects to transform existing 4-core and 8-core processor into multi-core processor and realize joint development of computer network information system and intelligent multimedia technology so as to further reflect humanistic features of computer information intelligence and promote the development of computer information technology towards more advanced direction.

Second, high integration of micro electronic technology. It aims at reducing actual volume of hardware attached by current electronic information technology and meanwhile further improving computer operating efficiency without influencing computer performance. Nanotechnology has been widely applied in China and even the world. It has greatly promoted the realization of integration of electronic information technology and made micro electronic technology present integrated development features and trend. Micro electronic products such as frga and arm have appeared on the market successively. This shows that high integration of micro electronic technology of human beings has been gradually popularized in human society.

Finally, opto-electronic information technology. It is a core electronic information technology that China expects to rely on in the future. As opto-electronic technology involves multiple fields of multimedia technology such as storage and display, it has presented a good development trend 
currently. Opto-electronic information technology will realize technical coverage in multiple fields such as medical treatment, agriculture and military and provide more development opportunities and economic benefits for social construction in the future. High-power semiconductor laser and solid laser have begun to display their talent. Meanwhile, LED light based on energy conservation and environmental protection has been gradually popularized by urban construction in the field of opto-electronic display. Such progress of electronic information technology is obvious to all ${ }^{[3]}$.

\section{Conclusion}

In conclusion, application advantages of electronic information technology have been recognized by people. Therefore, various countries endeavor to constantly expand technical application scope and increase technical content, promote diversified innovation of electronic information technology in the future under the premise of grasping its development direction and expect to occupy a higher position in the international market through leading high technologies and create more practical value for national construction.

\section{References}

[1] Wu Chao, Discussions on Application Features and Future Development Trend of Electronic Information Technology, Information Construction, 2015(12):67.

[2] Wu Wei, Study on Existing Problems of Electronic Information Technology in China and Countermeasures, Electronic Testing, 2016(19):177-178.

[3] Zhou Feifei, Problems in Development of Electronic Information Technology after Entry into Information Technology Era and Development Trend, Electronic Production, 2013(22):119-119. 